DOI: 10.20472/IAC.2019.048.055

\author{
ANNELOU VERNOOIJ \\ Wageningen University \& Research, Netherlands \\ ANNA MARIE FISKER \\ Aalborg University, Denmark \\ ANNA EVA UTKE HEILMANN \\ Aalborg University, Denmark \\ NINI CAMILLA BAGGER \\ Aalborg University, Denmark
}

\title{
TASTE MISSIONS - A NEW AND INNOVATIVE APPROACH TO IMPROVE PUPIL'S HEALTH THROUGH FOOD LITERACY
}

\begin{abstract}
:
What makes food, health and children so interesting? Food is one of the primary sources to human life that through a healthy lifestyle can be influencing the future of every individual. Especially children with their future ahead are an important target group that needs focus, since habits are often established at an early age (Piaget, 1969), which also is the case in regards to food and health. To secure the public health and wellbeing of future generations, and to ensure a more sustainable environment and world, we find that teaching children about food, nutrition and health is essential in order to develop a healthy relationship to food and eating habits (Başkale, et al., 2009). Learn4Health, an EU Erasmus + project, was created in 2016 to develop new and innovative methods to food literacy in European schools, to promote a broader knowledge of the origin of food and food systems, and to foster better health practices through new knowledge and self-efficiency. In the project, we seek to develop several innovative and new approaches that aim to increase food knowledge through interdisciplinary hands-on activities. It is our belief, that such methods can foster motivation and a better understanding of when, what and how food is grown, and thereby improve pupils action competencies in relation to food and health now and in the long-term.

This paper focuses on one of the Learn4Health activities, Taste Missions, developed, implemented and evaluated by Wageningen University \& Research and aims to illustrate how hands-on food activities can benefit pupils in European public schools. Further, it will describe, analyze and conclude upon the activity, and finally, summarize by discussing Taste Missions in the larger Learn4Health context and in the broader perspective of the public by presenting the HOFA Handbook.
\end{abstract}

\section{Keywords:}

Food literacy, Learning, Hands on Food Activities, Health, Interdisciplinary

JEL Classification: 100, I10, 129 


\section{Introduction}

What makes food and health so interesting? Food is one of the primary sources to human life that through a healthy lifestyle, can be influencing the future of every individual. Food and health are interlinked and intertwined and affecting the body, regardless of what we might think. Food has in recent years become a trend and interesting topic of discussion for many, and as time and knowledge change, so do people. We experience a turn in food and food knowledge; food can no longer just be food. For many it is a religion or way of life, a medium to socialize or the exact opposite. Food is being discussed over and over again and so does the discussion of health that inevitably follows. Constantly we are told by health educators all over the world that 'you are what you eat'. The phrase is spoken by many through times, but there are still doubts in who was the inventor of that specific quote. In 1826 Jean Anthelme Brillat-Savarin wrote in the book Physiologie du Gout, ou Meditations de Gastronomie Transcendante:" Tell me what you eat and I will tell you what you are" (Brillat-Savarin, 1826). Later in 1863/4 Ludwig Andreas Feuerback wrote:" Der Mensch ist, was er ibt." that translated into English is:" a man is what he eats." (Cherno, 1963). The quote as a whole is not found until the 1920's and 30's when the nutritionist Victor Lindlahr, developed the catabolic diet as a conclusion of his belief that food controls health. In 1942 Lindlahr even published a book with the title:" You are What you eat: how to win and keep health with diet." (Lindlahr, 1942). As times, economy and the world changes, so does the people and the sociology of man. The groupings in public was no longer just based on economy and religion, food and dietary guidelines became a grouping factor establishing new groups in society, such as vegetarians did in the 1960's.

Nowadays the line is often used in public when the aim of conversation turns to realization in what you eat or how you look. The phrase is now more a way of saying that obviously, one must understand that if you eat something greasy and fat, no wonder you turn up looking like that as well. The line has become a one-liner easy for everyone to state both in regards to the health of oneself, but also when it comes to relatives, friends etc. and comes with a background notion that to be fit and healthy, you need to eat good food. Food is indisputably connected to the body and how one look. Food is nutrition, vitamins, carbohydrates, fat and proteins that determine how a body looks, act and react, so maybe the line also has a sense of realism attached to it, but what happens if we turn the quotation around; you eat what you are? Food has become part of our personal identity, culture and for some even a religion. While we witness many food trends, an increase in health-related sicknesses has occurred. These count multiple noncommunicable diseases e.g. heart disease, type 2 diabetes, cancer etc. in a consequence of malnutrition, while on the other hand undernutrition as consequence of malnutrition are still a growing problem in other parts of the world caused by hunger and poverty. There is a world of differences between the two, but common for all is malnutrition.

In recent years, especially obesity has increased and stands out as one of the sinners to liferelated diseases, even for children. Obesity is a grown problem in the western world, yet a lot of different studies have shown that knowledge about health, food, nutrition, physical activity etc. has an effect on how people act and behave in regards to exactly this (Holm, 2012), why governments and ministries in a lot of countries, if not every country, is focusing on having public health recommendations. In the wake of this, the EU Erasmus+ project Learn4Health was 
created in 2016 to establish new and innovative learning methods to food literacy for pupils in European schools, to foster health through new knowledge and self- efficacy and thereby cause behavioral change beneficial for children, parents and grandparents now and in the future.

\section{Learn4health}

Learn4health is an Erasmus+ Strategic Partnership project established with the aim of improving children's health while creating awareness and knowledge transfer about food, food origin and food and health. The project was created on the basis of several studies showing European problems within the fields of child obesity, malnutrition and health in order to prevent an increase in lifestyle diseases now and in the long term. Currently, a lot of regulations and policies have been dealing with the national and European problems, yet no actions have yet enhanced pupil's food literacy sufficiently. Learn4Health aims to establish new learning methods for teachers to increase the general understanding of food and health at an early age, as it is our belief that having knowledge on their own, children will be able to act in a more sufficient, responsible and healthier way in the long term, preventing obesity and lifestyle diseases and thereby increase public health generally.

In the project several programs are being developed, which all aim to increase food knowledge through hands-on activities. Studies show that methods as hands-on activities foster motivation and a better understanding of when, what and how food is grown, produced or in other ways handled. Learn4Health is an EU Erasmus+ Programme that includes twelve organizations from six European countries; Denmark, Spain, Slovenia, The Netherlands, United Kingdom and Lithuania. This paper intends to describe, discuss and conclude upon one of the programmes developed through the Learn4Health; Taste Missions. Further, it will summarize by including the Taste Missions in the broader perspective under the theme of Children and health and thereby include the overall mission of the Learn4Health project by describing the generalizability of the developed programmes with the HOFA Handbook; The final product of Learn4Health.

First and foremost, the background for Taste Mission will be described.

\section{Taste Lessons}

In the Netherlands, nutrition education is not mandatory in primary schools. Nutrition education has to compete with a lot of subjects and a busy schedule of schools and teachers. Also, in general, primary schools in the Netherlands don't provide a school lunch, which means that children bring their own sandwiches, drinks and snacks or have lunch at home. Thereby the focus on food, nutrition and health in general are being neglected, despite the fact that knowledge and competencies within food often provide better and more sustainable actions now and, in the future (Dyg, 2012). Nowadays consumers, especially children, are increasingly disconnected from the understanding of how and where their food is produced and the gap between food and the consumer, in this case the children, is getting bigger, while lifestyle diseases caused by malnutrition and obesity are increasing in the western world (Dyg, 2014). Often lack of food knowledge and the increase of obesity is being compared and with good reason, as several studies have shown these are often interlinked (Dyg, 2012) (Rush \& Yan 2017) (Colatruglio \& Slater, 2014). It is on the basis of these findings that Wageningen University 
\& Research started developing a school-based nutrition education programme called Taste Lessons that later became part of the Learn4Health programme.

The aim of Taste Lessons is to increase children's knowledge and interest in food as well as their knowledge and skills regarding healthy and conscious eating behaviour. Taste Lessons contains five lessons discussing various topics in relation to five themes; taste, nutrition and health, food production, consumer skills and food preparation. For each grade are specific lessons. The lessons are written and designed in such a way that they arouse the curiosity of children about their food, as food should equalise fun! Children perform all kinds of experiments by using their senses (taste, smell, touch, sea, hear) and become aware of their taste preferences and factors that influence preferences. All in a positive and playful way. In addition, children discover new food products (including their flavours) and learn about food production systems and health effects of food. Since the start of Taste Lessons in 2006, more than 70 percent of all primary schools in the Netherlands have participated in the programme.

\section{Research}

In the period 2011-2012 scientific research has been done to assess the effect of Taste Lessons on behavioural determinants towards healthy foods (Battjes-Fries et al., 2015). In total 1183 children, aged between 9-12 years old from twenty-one different primary schools participated. In the intervention group, teachers implemented the Taste Lesson programme and afterwards children filled in three questionnaires. The control group received no lessons in food education. Results were collected at baseline, four weeks and six weeks in both the intervention and control group. Results showed that the intervention group showed a higher increase in knowledge about healthy and sustainable eating. Six months after the Taste Lessons this knowledge was still present compared to the children who did not follow the Taste Lessons. Additionally, Taste Lessons stimulate children to learn about food and the lessons create a social norm that encourages children to taste unknown products and to eat healthier (ref.).

Active involvement of children is seen as an important factor in nutrition education (Jones et al., 2012). It's very important that children experience their food and not only learn about food as abstract concepts, which is why they need to be actively involved and gain interest in the nutritional education programmes (Pérez-Rodrigo et al, 2001). Therefore in 2013, Wageningen University \& Research decided to add four additional learning activities to the Taste Lessons programme and to investigate if the programme may be more effective by adding these elements (Battjes-Fries et al, 2016). The additional activities were: a vegetable quiz, supermarket assignment, excursion to a vegetable grower and an extended cooking lesson with a dietician.

Thirty-three primary schools (877 children, 8-11 years old) were involved in this study, they performed a taste test and filled out a questionnaire. Results showed that when Taste Lessons is linked to experimental activities, more and stronger effects on knowledge and in several psychosocial determinants were found. No significant results were found on the level of behaviour. The results suggest that experimental learning methods might indeed increase the effectiveness of a nutrition programme like Taste Lessons. These results have been used to 
further innovate the Taste Lessons programme and therefore in 2016 Taste Missions were developed.

\section{Taste Missions}

Taste Lessons can be extended with more comprehensive Taste Missions. A Taste Mission is a digital, interactive and innovative way to connect hands-on activities to a broader food education programme by making use of principles of gamification. The subject of a Taste Mission is always one basic food group, such as vegetables, dairy or fruit. It aims to deepen children's understanding of the lessons by involving children in each step of the food chain with various hands-on-activities.

The focus is on discovering the origin of food. A Taste Mission consists of lessons and handson activities. Every Taste Mission always consists of (1) an introduction to the mission via the interactive whiteboard, (2) lessons inside the classroom, (3) an excursion to a food grower or food company, (4) visit to a supermarket or other food shops and (5) a cooking assignment.

Every Taste Mission is introduced by a main character who challenges the children to learn more about their food. During the lessons, the main character provides the children with feedback via the interactive whiteboard. In total there are nine Taste Mission developed in the Netherlands, see Table 1.

\begin{tabular}{|l|l|}
\hline Subject Taste Missions & Age target group \\
\hline School garden & $4-8$ year \\
\hline Bread & $4-6$ year \\
\hline Dairy & $6-8$ year \\
\hline Fruit & $8-10$ year \\
\hline Drinks & $8-10$ year \\
\hline Meat, fish, legumes, eggs and nuts $8-10$ year \\
\hline Vegetables & $10-12$ year \\
\hline Oil \& fat & $10-12$ year \\
\hline Potatoes, rice and pasta & $10-12$ year \\
\hline
\end{tabular}

Table 1. Available Taste Missions in the Netherlands

\section{Taste Mission and Learn4Health}

As described all the Taste Missions are developed in Dutch. Because of the Learn4Health project, there was an opportunity to translate one of the Taste Missions to English, as with the Taste Mission Fruit, which is developed for children from 8-10 years old. Translating the Taste Mission brought some difficulties due to the different dietary guidelines per country and the fact that they were often only available in the native language. Therefore, a separate Taste Mission for each country was made.

A Taste Mission always consist of a main character who challenges the children to help with a certain problem. In the Taste Mission Fruit for the Netherlands, this is done by a chef of a very good and well-known restaurant in the Netherlands. But children in England and Denmark don't 
know him. It is preferable if the main character is a 'famous' person of the country, as he or she can function as a role model and the children can relate with this character, recognize him/her and will become enthusiastic to help him/her. A new suitable main character was therefore sought and for the international versions of the Taste Mission Fruit, Prue Leith, CBE was used as a main character.

After the translation, the possibilities and applicability of Taste Missions was tested by schools in Denmark and the United Kingdom. The school in Denmark was very enthusiastic about the Taste Mission (Figure 1). They gave very high scores for the Taste Mission and have expressed great enthusiasm and wishes to do the other Taste Missions if there is a possibility to translate them as well. The school in Denmark indicated to repeat the Taste Mission Fruit next school year.

The children of the school in the United Kingdom enjoyed the Taste Mission, they indicated the taste sessions and discovering new sorts of fruits as their favorite. The teacher of the school in the United Kingdom gave the Taste Mission as a project.

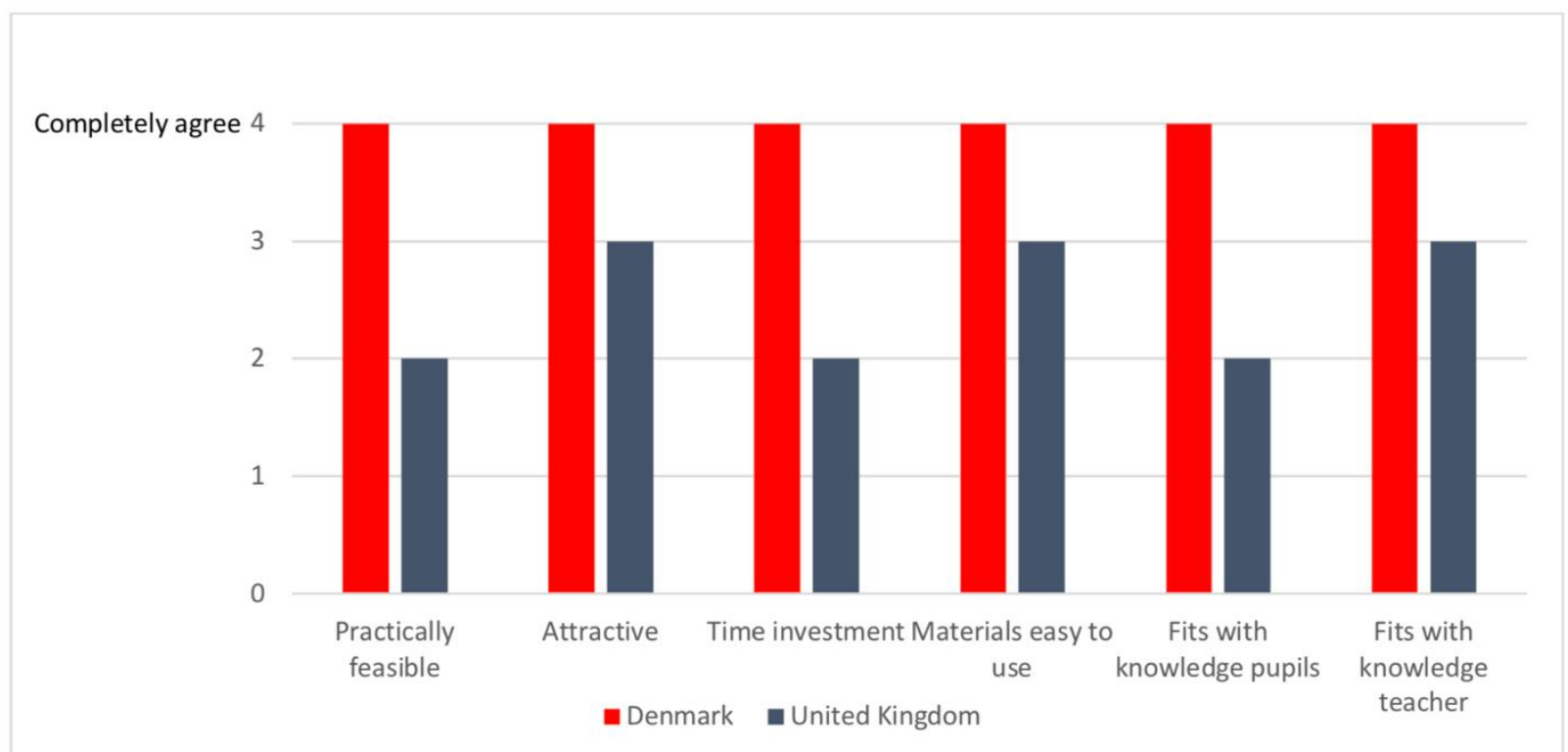

Figure 1. Experiences Taste Mission Fruit.

Based on the results it can be concluded that Taste Missions are feasible and easy to implement by other countries. With this module, a school can connect hands-on food activities with lessons in the class in an innovative way which is also proven to be effective. In the ideal situation, you want to have a unique version for every country that wants to work with the Taste missions. In this way, it fits best with the knowledge and experiences of the children and the dietary guidelines of the country can be applied.

\section{Other activities in Learn4Health}

In order to fulfil the goals of Learn4Health, several programs have been developed to enhance children's knowledge of food and health. In Denmark, The Mobile Sprout Wagon has been 
developed as a unique teaching instrument at Arden School in close collaboration With Aalborg University and the Danish Architect Hans Ramsgaard Møller.

The Sprout Wagon is a mobile steel construction on wheels; a wagon, designed to carry trays to grow sprouts, complete with its own adjustable water and light system. It is designed as a micro system to mirror natural conditions, with the intention of providing pupils with an educational and hands-on approach to learn about the process of growing their own sprouts. The Sprout Wagon is designed and constructed through an interdisciplinary collaboration between architects and engineers at Aalborg University and school teachers at Arden School in Denmark. The Sprout Wagon is based in a common area alongside the school canteen, but its mobile design makes it possible to move it around e.g. into the classrooms, where it can be used in experiments in multiple school subjects and across several classes and age groups. The aim is to make use of the Sprout Wagon in a wide range of relevant science subjects; the adjustable light, water and temperature make it possible for pupils to experiment, measure and calculate, while administering the necessary nutrition, for the sprouts to grow and flourish. Further, complex concepts such as the photosynthesis can be illustrated, taught and explained in an understandable, hands-on way. The various sprouts that blossoms of this collaborative approach between pupils and teachers are then available for pupils to harvest for e.g. their lunch, or use in home economic classes.

Another project within the Learn4Health project, also at Arden School in Denmark, is the Squash Competition. The Squash Competition is a new hands-on learning context that engages pupils and teachers in a school garden program. It is a pedagogical program oriented towards the teachers, which further links the classroom to the natural surroundings (Larsen, 2018). Primarily, the program contains a Squash-growing competition, but it has a wide applicability, as it is possible to replace the Squash with any other vegetable depending on the surrounding possibilities i.e. season and country. The Squash competition is based on a learning guide, constructed for the teachers to involve the students in growing the most amounts of squash measured in kilos. The teacher's manual is meant as a guide that aims to involve the children in growing vegetables while enhancing the knowledge behind. It is the intention that the children, first and foremost is taught about the photosynthesis. Secondly, they are to discover the best way to grow their vegetable, through searching, reading and thereby being able to conclude upon the most beneficial ways in order to establish a hypothesis on what they believe would be the most beneficial circumstances to grow the largest amount of squash in kilos (Larsen, 2018). Next, the pupils are then to weigh and measure the squash, during the period to follow its growth, and at a certain deadline, harvest their crop. The program is designed in a way that makes it possible to include in several educational surroundings i.e. school garden, the classroom, the kitchen etc. which thereby creates a room for new and innovative methods to be used in different coherences to enhance the existing knowledge within any science subject while establishing new knowledge as well. Concurrently, the intention is to collect, prepare and taste healthy dishes containing squash and finally share their whole experience with Learn4Health participating schools and partners (Larsen, 2018).

In the long term, the aim is to increase the pupils' knowledge of the food they eat, to empower them and give them the ability to choose, prepare and eat food, beneficial for their health now 
and in the long term, while having fun. The competition part can create variety to the existing school subjects and the intention is that the learning process can be experienced as a game and create a fun context, which can benefit the learning progress as well as the interaction between the children. Furthermore, it can provide the pupils with a sense of self-confidence and creating new friendships across class divides, year group etc. and thereby stimulate and improve social abilities (Lowe, 2014; Dyg \& Wistoft, 2018).

A third project within Learn4Health is the WannaB Foodie Entrepreneur, a project made in a collaboration between the two Slovenian partners, the France Prešeren Črenšovci Primary School, and the Centre for Health and Development Murska Sobota. The project involves school-owned raised garden beds, where the pupils can grow and cultivate traditional herbs and crops. The harvested results will be showcased and sold at stands manned by the pupils

at a local market and festival, where local food and culture is promoted. The intended impact of this project is a better understanding of food origins and production for the pupils, while strengthening their entrepreneurial skills. The new and innovative aspect of the project is that the pupils will not only be involved with the growing of herbs and crops, connecting them to nature, they will also harvest their crops and sell them, which will teach them invaluable, practical skills in the field of small businesses. The involvement in the local festival and markets is further intended also to preserve local culinary culture and history; stressing the importance of healthy, local food for both pupils and their families. It is also the intention that this program should be seen as strengthening the intergenerational connections; connecting kindergartens, school and the local community.

Several studies have shown the connection between school gardens and garden-based learning and nutritional and environmental awareness, well-being as well as new learning achievements among children (Dyg, 2014; Dyg \& Wistoft 2018; Waliczek \& Zajicek, 1999). The Sprout Wagon, Squash Competition and WannaB Foodie Entrepreneur are all examples of how new, interdisciplinary and innovative approaches to school gardens and garden-based learning can be developed in praxis. These programmes are all designed to fit Learn4Healths overall aim of creating new interdisciplinary ways to promote the understanding of health, food and nutrition and the origin of food to children (Larsen, 2018).

\section{HOFA Handbook}

As a final result of the Learn4Health Project, The HOFA Handbook is developed as a manual for teachers and students that includes teaching instruments to new and innovative programmes to be implemented at schools worldwide. The HOFA Handbook includes a description of the Learn4Health project, a list of participating partners, a thorough and exact description of each activity and the possibilities of up- or down-scaling the activity. Further, the activity description will include some of the experiences, challenges and recommendations that each responsible partner has been considering, as well as pictures to visualize the activity even further.

HOFA Handbook, a complete instructional guide book offering detailed instructions and curricula guides to the different Learn4Health activities. These thorough guides and manuals will ensure that other EU schools interested in doing a similar activity will have a finished "recipe" for implementing their own. All this material will be collected in the Learn4Health HOFA 
Handbook. The HOFA Handbook will be produced as a book in PDF format and be available through the Learn4Health website at the end of the project, freely accessible for all interested schools across Europe. The open access will secure wide applicability, dissemination and great transferability. The HOFA Handbook will secure the sustainability of the Learn4Health project, as the insights, experiences and the knowledge accumulated within the project period will be passed on to a wide audience, easily available for application, and therefore also optimizing the overall impact nationally and internationally.

Primarily, the Handbook will be published in English and secondly in other Learn4Health relevant languages to provide the reader with the best possible outcome when wishing to implement one or more activities.

\section{Conclusion}

To secure the public wellbeing and health of our future generations, and to furthermore assure a more sustainable world, it is essential that we add focus on the importance of teaching children about food, food production, nutrition and health. This has been the overall goal and aim of the Learn4Health project, an EU Erasmus+ project, which was created in 2016 to develop new and innovative methods to food literacy in European schools, to promote a broader knowledge of the origin of food and food systems, and to foster better health practices through new knowledge and self-efficiency. In this paper, we have presented the project Taste Missions, developed, implemented and evaluated by Wageningen University \& Research, and discussed how this project can connect hands-on food activities with class lessons in an innovative and effective way to increase food literacy in children. Furthermore, we have presented and discussed two other projects within Learn4Health, as well as the HOFA Handbook, to place Taste Missions in the larger Learn4Health context. This is key to illustrate how the overall activities, approaches and results of this project can foster motivation and a better understanding of when, what and how food is grown, and thereby increase children's knowledge and interest in food as well as their knowledge and skills regarding healthy and conscious eating behavior now and in the future.

\section{References}

Başkale, H., Bahar, Z., Başer, G., \& Ari, M., (2009) Use of Piaget's theory in preschool nutrition education, Rev. Nutr. 22 (6).

Battjes-Fries, M.C., Haveman-Nies, A., Renes, R.J., Meester, H.J. \& van 't Veer, P. (2015). Effect of the Dutch school-based education programme 'Taste Lessons' on behavioural determinants of taste acceptance and healthy eating: a quasi-experimental study. Public Health Nutrition, 18 pp. 223141.

Battjes-Fries, M.C., van Dongen, E.J., Renes, R.J., Meester, H.J., van't Veer, P. \& Haveman-Nies, A. (2016). Effectiveness of Taste Lessons with and without additional experiential learning activities on children's psychosocial determinants of vegetable consumption. Appetite, 105 pp. 519-26.

Brillat-Saverin, J. A. (1826). The Physiology of Taste. France: JSTOR Journal of the History of Ideas, vol. 24 , 
Cherno, Melvin. “Feuerbach's 'Man Is What He Eats': A Rectification."no. 3, 1963, pp. 397-406., www.jstor.org/stable/2708215.

Colatruglio, S \& Slater, J. (2014). Food Literacy: Bridging the Gap between Food, Nutrition and Wellbeing. In: Deer, F., Falkenberg, T., McMillan, B., Sims, L. Sustainable well-being: Concepts, issues and educational practices. Winnipeg, MB: ESWB Press. pp. 37-55.

Dyg, P. M. (2012). Farm-School Collaboration and the underlying motivation, values and learning goals - Enhancing childrens' academic learning and fostering food citizenship? In The 10th European IFSA Symposium - Producing and reproducing farming systems: New modes of organisation for sustainable food systems of tomorrow (pp. 21-22).

Dyg, P. (2014). Fostering Food Literacy and Food Citizenship through Farm-School Cooperation and beyond. Ph.D. Aalborg, Denmark: Department of Civil Engineering, Aalborg University.

Dyg P M. \& Wistoft K. (2018). Wellbeing in school gardens - the case of the Gardens for Bellies food and environmental education program, Environmental Education Research, DOI: 10.1080/13504622.2018.1434869

Jones M, Dailami N, Weitkamp E, Salmon D, Kimberlee R, Morley A, et al. (2012) Food sustainability education as a route to healthier eating: evaluation of a multi-component school programme in English primary schools. Health Education Research. 27(3):448- 58.

Larsen, V. A. (2018). Teacher Manual for Soil'n Garden program (SGP). Arden, Denmark.

Lindlahr, V. (1942). You Are What You Eat. 5th ed.: National Nutrition Society, Inc.

Lowe, C. F., Horne, P. J., Tapper, K., Bowdery, M., \& Egerton, C. (2004). Effects of peer modelling and rewards-based intervention to increase fruit and vegetable consumption in children, European Journal of Clinical Nutrition 58, p510-522.

Pérez-Rodrigo C, Aranceta J. (2001) School-based nutrition education: lessons learned and new perspectives. Public Health Nutrition. 4(1A):131-9.

Piaget, J. (1969). Barnets psykiske udvikling. København: Hans Reitzels Forlag A/S. p20-35.

Rush, E C \& Yan, M R. (2017). Evolution not Revolution: Nutrition and Obesity. Nutrients. 9 (5), 519.

Waliczek, T.M., Zajicek, J.M. (1999). School Gardening: Improving Environmental Attitudes of Children Through Hands-On Learning. Journal of Environ. Hort. 17(4): 180-184. 